\title{
Davidson, first-person authority, and the evidence for semantics
}

\author{
Steven Gross
}

\section{Introduction}

Donald Davidson aims to illuminate the concept of meaning by asking: what knowledge would suffice to put one in a position to understand the speech of another, and what evidence sufficiently distant from the concepts to be illuminated could in principle ground such knowledge? Davidson answers: knowledge of an appropriate truth-theory for the speaker's language, grounded in what sentences the speaker holds true, or prefers true, in what circumstances. In support of this answer, he both outlines such a truth-theory for a substantial fragment of a natural language, and sketches a procedure-radical interpretation - that, drawing on such evidence, could confirm such a theory. Bracketing refinements (such as those introduced to accommodate context-sensitivity), the truth-theory allows the derivation, from finite axioms, of theorems of the form " $\mathrm{S}$ is true in $\mathrm{L}$ iff $\mathrm{p}$ " for all sentences of the target language $\mathrm{L}$, where " $p$ " is replaced by a sentence that can be said to interpret the target sentence $\mathrm{S}$. The radical interpreter confirms such a theory in application to some speaker if, while thus interpreting the speaker's sentences, she can also attribute to the speaker attitudes that, given what sentences the speaker holds true in what circumstances, plausibly optimize her rationality and possession of true beliefs.

Radical interpretation, Davidson maintains, underdetermines truth-theory. What is more, in his view, such underdetermination amounts to indeterminacy. The evidence available to a radical interpreter, given the constraints to which radical interpretation is subject, exhausts the relevant semantic facts, in the sense both of determining them and rendering them epistemically determinable. (Henceforth "(E)" for "exhaustion.") Thus, truth-theories equally well confirmed by all the evidence equally well capture all the facts to be captured. ${ }^{1}$ This is so even if the truth-theories provide, for the same

\footnotetext{
1 My fact-talk follows Davidson and, following him, Lepore and Ludwig (2005). Davidson, however, does not admit fact-entities into his ontology, so this fact-talk should not be so construed.
} 
sentence, truth-conditions that from the interpreter's perspective are incompatible or differ in some other semantically relevant way. According to Davidson, (E) reflects the fact that meaning is "essentially public," and all readily observable evidence is available to a radical interpreter.

(E) occupies a central position in Davidson's philosophy, and some of his most distinctive claims in epistemology and metaphysics - the impossibility of alternative conceptual schemes, the impossibility of radical error about the external world-seem to rest upon it at least in part. It can be seen as the most basic expression of the antiCartesianism that pervades Davidson's work. But what is the basis of (E) itself? Lepore and Ludwig (2005) find themselves unable to reconstruct a persuasive Davidsonian argument in its favor. They allow, however, that:

It may be that on issues as fundamental as these, no wholly persuasive and non-question-begging arguments will be available, and that the choice between different stances must be made on holistic criteria, that is, considerations about how well (though imperfectly) each position accommodates the weighted totality of our pre-analytic beliefs. (2005, pp. 391-2)

It is thus crucial whether $(\mathrm{E})$, alone or in concert with other plausible claims, has implausible consequences.

Lepore and Ludwig put forward two major objections to (E), or at least to its basis in Davidson's conception of the concepts central to interpretation (the concepts of meaning, belief, desire, intention, and so on-henceforth, interpretational concepts). According to the first, $(\mathrm{E})$, or its basis in Davidson's conception of interpretational concepts, is in tension with first-person knowledge and authority. According to the second, the resulting indeterminacy is problematic, as it forces the interpreter to treat as equivalent in a semantically relevant way certain sentences in her own language that she knows not to be thus equivalent. Lepore and Ludwig are, of course, not the first to question Davidson on these counts. But they develop their points in distinctive ways that demand close attention.

What follows mostly concerns Lepore and Ludwig's first objection. I argue that they do not establish that $(\mathrm{E})$ is in tension with first person knowledge of and authority over one's own mental states, even if they are right that Davidson's attempt to explain an aspect of the asymmetry of first- and third-person knowledge fails. In particular, I argue that they do not sufficiently distinguish two claims: (i) that the evidence available to a radical interpreter suffices for his recovering all the semantic facts, and (ii) that for someone to ascribe with warrant an attitude or meaning to a speaker or the speaker's words, he must do so on the basis of such evidence. ${ }^{2}$ And I argue that they do not provide reason to think an accurate first-person ascription could conflict with a radical interpreter's third-person ascription. Lepore and Ludwig's objection that indeterminacy

2 To reduce potential confusion, I use male pronouns for the interpreter and female pronouns for the subject of interpretation (when the subject is not the interpreter). Also, I will often use "interpreter" as shorthand for "radical interpreter." 
is problematic indeed provides such grounds, but then we have no independent objection from first-person authority. After discussing whether an appeal to first-person authority plays any essential role in the indeterminacy objection, I conclude by briefly suggesting that, at least given a further claim Lepore and Ludwig endorse concerning the relation between semantics and semantic competence, there are other sources of information concerning the semantic facts, available neither to the radical interpreter nor first-personally to the subject, that do provide a challenge to (E): namely, non-readily observable, non-first-person-accessible evidence of the sort sometimes drawn upon, for example, in psycholinguistics and the cognitive neuroscience of language.

\section{Self-ascription and the interpreter's evidence}

Lepore and Ludwig identify the following sufficient condition for indeterminacy: there is underdetermination relative to all relevant evidence, and the non-observational concepts of the underdetermined theories are "purely theoretical": that is, their content "is exhausted by their application in the domain of evidence in a way that results in the content of the theories' theoretical claims not transcending their predictions about facts in the domain of evidence" (2005, p. 225). Davidson, they argue, maintains that interpretational concepts are purely theoretical in this sense (henceforth, (PT)). But this, they claim, is in tension with something else Davidson accepts: that one typically knows one's attitudes, whereas others may or may not, and one typically does so in a different manner-non-inferentially-and with a particular presumption of warrant that inferential ascriptions of attitudes lack.

Lepore and Ludwig press this challenge from first-person knowledge and authority in two ways. Their first argument is intricate, and so is worth quoting in full:

If concepts such as those of meaning, belief, intention, and so on, are treated as purely theoretical, relative to some sort of evidence, the interpreter's application of these concepts to himself must be treated in the same way. The difficulty with this is ... it requires an account of the interpreter's knowledge of evidence for the application of such concepts (for the moment we focus on attributions to others) which does not presuppose he knows independently whether such concepts apply, not only to others, but to himself. For otherwise the content of the concepts would prima facie not be exhausted by their role in accounting for such evidence. But whether or not one accepts the assumption of the Cartesian skeptic that, globally, knowledge of one's experiences and conscious mental states is epistemically prior to one's knowledge of one's experience of events in one's environment, it's very difficult to account for our knowledge of particular events in our environment without presupposing knowledge of representational perceptual experiences. If someone knows that a tree is in front of him, or that a cap is on his lap, it is (special circumstances aside) at least in part on the basis of his perceptual experiences. Since attributions of representational perceptual experiences cannot be made apart from treating their subject as a believer, knowledge of such experiences (that one has one and what it represents) would seem to presuppose knowledge of the application of concepts in the proscribed range in 
our access to what is treated as ultimate evidence for their correct application. If, as seems correct, all knowledge of the occurrence of particular events in our environment rests in part on knowledge of perceptual experience, then we cannot represent the concepts in question as purely theoretical concepts relative to such evidence, at least if we can know the concepts apply to anything. If this is right, then if we are in an epistemic position to apply these concepts to anything, they cannot be treated as purely theoretical concepts introduced fundamentally to help us systematize behavior. (2005, p. 228)

A radical interpreter, in interpreting another, must advert to knowledge of his own experiences. This in turn requires applying proscribed concepts in order to access the evidence on which they may base their interpretations. And this in turn requires that interpreters already have knowledge of the application of these concepts. But then the content of these concepts is not exhausted by their role in systematizing behavior, since, in order for them to play that role, they must already have application (to the interpreter) prior to any attempt to systematize behavior.

One might attempt to block this argument by questioning whether perceptual beliefs are epistemically grounded in representational perceptual experiences, or by questioning whether, if they are so grounded, this grounding must advert to knowledge (or belief) that one has such a representational perceptual experience, as opposed to adverting simply to the experience itself. These moves may or may not have merit, and are certainly worth exploring. But I want to focus on another point.

Lepore and Ludwig's argument requires that, if a concept is purely theoretical, it can only be applied with warrant on the basis of possessed evidence from the relevant domain. The interpreter violates this requirement in ascribing to himself representational perceptual experience. It is in the nature of the case that this violation could not be remedied by adverting to evidence drawn from the interpreter's own behavior (and holds-true attitudes and environment). For that evidence could in turn only be known (whether by himself or by some other interpreter) by ascribing to the knower further representational perceptual experiences not themselves based on evidence in the domain - and so on, without hope of ever finally purging the evidential base of the proscribed concepts.

But why can purely theoretical concepts only be applied with warrant on the basis of possessed evidence from the relevant domain? Lepore and Ludwig could build this requirement into their definition of "purely theoretical," but then it would be open to Davidson to substitute an alternative notion also sufficient for indeterminacy (given the existence of incompatible theories that equally well accord with all the relevant evidence). Such a notion is available if we distinguish (i) a concept's content being exhausted by its application to a domain of evidence, and (ii) its being applicable with warrant only when one is systematizing such evidence. The interpreter, in applying interpretational concepts to himself, indeed does not apply them in systematizing his own behavior. (It is irrelevant that in this case he is applying them indirectly in order to systematize behavior: that is, by applying them in order to access evidence concerning another's behavior.) But from this it does not follow that the concepts' content is not 
exhausted by its application to the relevant domain of evidence. What does follow is that true ascriptions involving these concepts cannot transcend their predictions about facts in the domain of evidence. Thus, an accurate self-ascription involving interpretational concepts cannot conflict with warranted ascriptions that are made on the basis of all the evidence available to a radical interpreter subject to the constraints imposed in radical interpretation: the interpreter's self-ascription cannot conflict with the results of his being radically interpreted. Someone can warrantedly self-ascribe a mental state, however, even if he does not himself do so on the basis of this evidence, which he need not even possess. Or at least being a purely theoretical concept, in this sense, need not preclude this-for all that has been shown.

One might reply on Lepore and Ludwig's behalf that I have missed a central element of their argument. For I allow that an accurate self-ascription involving interpretational concepts cannot conflict with warranted ascriptions that are made on the basis of all the evidence available to a radical interpreter subject to the constraints imposed in radical interpretation. And this presumes that someone-a radical interpreter-could be in possession of just this evidence. But the argument shows that this is not so, since in order to possess the evidence the interpreter would need also to possess evidence about his own mental states. (In the case at hand, this would be an interpreter of the interpreter.) Again, the interpreter must therefore make use of proscribed concepts and thus evidence not sufficiently distant from the concepts to be illuminated.

This reply, however, would conflate a constraint on the evidence with a supposed constraint on how one comes to know the evidence. The constraint on the evidence is that it not involve the precluded concepts. But this does not place a constraint on how the interpreter comes to know the evidence upon which he may draw. In particular, it does not bar in the interpreter from applying the proscribed concepts in coming to have the relevant evidence. Whether he does is neither here nor there. The question is whether, once he has the relevant evidence, he can come to interpret the speaker, drawing upon only this evidence (subject to the usual constraints). Other evidence, however gained, falls by the wayside-including evidence used in gaining the evidence used in radical interpretation. (Compare discussions of whether one can in principle $a$ priori deduce the mental facts from the physical facts. That one's knowledge of the physical is not a priori is not relevant here, nor is any reliance on the ascription of representational perceptual experiences in coming to know the physical facts.) Indeed, perhaps it's not even relevant whether the radical interpreter comes to know the evidence, or even knows it, at all. It might suffice, for Davidson's purposes, that a radical interpreter who has the evidence can interpret the speaker-whether the evidence were found in him innately, handed to him by god, or just supposed by him as a hypothetical.

A further aspect of Lepore and Ludwig's argument deserves comment. They conclude that the interpreter's need to self-ascribe proscribed concepts shows that these concepts, contra Davidson, are not "introduced fundamentally to help us system- 
atize behavior" (Lepore and Ludwig 2005, p. 228). But, they argue, facilitating such systematization is, according to Davidson, the point or role (as they also put it) of such concepts:

Everyday linguistic and semantic concepts are part of an intuitive theory for organizing more primitive data, so only confusion can result from treating these concepts and their supposed objects as if they had a life of their own. (Davidson 2001 (1974), p. 143)

One might therefore wonder whether my reply to Lepore and Ludwig fails to accommodate this fundamentality claim. Davidson, however, later writes that neither the first-person perspective nor the third is more fundamental than the other:

... knowledge of the objective world ...; knowledge of the minds of others; and knowledge of my own mind. None... is reducible to either of the other two... none is conceptually or temporally prior.... (Davidson 2001 (1998), p. 87)

So, Davidson in the previous quote is not best read as maintaining that theoretical concepts' being purely theoretical requires that they possess a fundamentality that precludes authoritative first-person ascription. The sense in which they are fundamental is rather captured by (PT) and thus (E): their correct application does not transcend the evidence available to a radical interpreter-in that sense, on Davidson's view, they do not possess "a life of their own." I do not see a further sense of fundamentality one could use to resuscitate Lepore and Ludwig's argument.

The question remains: why think that accurate self-ascriptions involving interpretational concepts cannot conflict with warranted ascriptions made on the basis of all relevant evidence subject to the constraints imposed in radical interpretation? But that they cannot follows immediately from (E), and we are examining arguments against (E), not attempting to argue for it. Thus, the relevant question for us is: why think things are not so? Lepore and Ludwig's first way of pressing the challenge does not supply any reason. Our reply to Lepore and Ludwig's second way foregrounds this question as well.

\section{First-person authority generally}

Lepore and Ludwig's second way of pressing the challenge appeals to first-person knowledge and authority generally - not just as it bears on the basis of a radical interpreter's evidence. They argue that $(\mathrm{PT})$ - that interpretational concepts are purely theoretical-is incompatible with the fact that we (typically) apply interpretational concepts to ourselves non-inferentially (in particular, not on the basis of evidence available to a radical interpreter) and with a special, though defeasible, authority.

The bulk of their discussion is actually not focused on developing this incompatibility, but rather devoted to a detailed critique of Davidson's attempt(s) to explain first-person authority by reference to the nature of radical interpretation. Davidson's main strategy is to explain the epistemic asymmetry of first-person and third-person belief ascriptions 
in terms of an asymmetry in knowledge of meaning that must be assumed by interpreters and that seems less open to sceptical challenge than the asymmetry with respect to belief attributions. Lepore and Ludwig object inter alia that the fact that interpreters must assume something does not explain why it is so, and that, in any event, the asymmetry in knowledge of meaning fails to yield the asymmetry in the warrant of belief ascriptions unless further asymmetries are assumed. (More on this below; for details, see Lepore and Ludwig 2005, ch. 20.)

The critique by itself, supposing it effective, does not challenge (PT). For that, one needs reason to think Davidson needs to explain first-person authority in order to maintain (PT). It cannot be — at least so far as Lepore and Ludwig are concerned - that any view of interpretational concepts must include such an explanation, for they maintain that first-person authority is too fundamental to admit informative explanation in terms of something more basic. Lepore and Ludwig's explicit statement of why Davidson in particular faces this challenge - their reason for maintaining (PT)'s incompatibility with first-person knowledge and authority-appears late in their discussion. There are Davidsonian insights, they argue, that provide more direct grounds for maintaining that interpreters must assume first-person knowledge than does Davidson's own attempted explanation. In particular,

... we count nothing as an agent unless it is by and large rational, and that presupposes that the coherence of its behavior in light of the attitudes we attribute to him expresses his knowledge of what he thinks. (2005, p. 372, cf. p. 368)

This again "provides no explanation of first-person knowledge, any more than the need to assume a speaker is by and large rational in order to interpret him explains why he is rational" (2005, p. 372). But, for reasons we turn to presently, they maintain that it does provide a challenge to $(\mathrm{PT})$. That it provides a challenge to $(\mathrm{PT})$ is presumably why Davidson is obligated to provide an explanation of first-person authority that is consistent with (PT): such an explanation would show that the challenge is only apparent. Perhaps it is unclear why an explanation is needed, even if it would suffice: would it not also suffice just to show that first-person authority is, contrary to the challenge, consistent with (PT)? But an explanation might go further in rendering (PT), and $(\mathrm{E})$, holistically attractive.

The challenge is this:

[The connection between rationality and self-knowledge] seems to show that [(a)] our a priori conception of a rational agent is one of a being who has non-inferential knowledge of its own psychological states, and, if it is a speaker, the meanings of its sentences, and [(b)] who therefore must regard its attempts to interpret others as attempts to discover facts which are not exhausted by what is recoverable from observations of behavior; [(c)] if there are two possible assignments of meanings and attitude contents to a speaker's sentences and attitudes, from the interpreter's standpoint, the possibility that one is right and the other wrong remains open, [(d)] because the interpreter must recognize the possibility of a perspective on those thoughts and meanings which is not dependent on recovering them from behavioral evidence. (2005, pp. 368-9) 
It may not be clear that the connection between rationality and self-knowledge, so far as Lepore and Ludwig develop it here, suggests that such a being must have noninferential (or, for that matter, authoritative) knowledge of its own psychological states. It seems only required that an agent know, at least for the most part, what its attitudes are. Lepore and Ludwig do not pretend, however, to have drawn out fully the implications of our a priori conception of a rational agent. Suppose it is granted that further reflection - perhaps indeed related to the sort sketched in their first challengesuggests (a). The logic of the argument, I believe, is then that (b) follows from (a), because (d) follows immediately from (a), (c) follows from (d), and (b), given that there is underdetermination, follows from (c).

The crucial step is from (d)'s "possibility of a perspective on those thoughts and meanings which is not dependent on recovering them from behavioral evidence" to (c)'s "possibility that one [assignment warranted by the interpreter's evidence] is right and the other wrong." But, without further development, (c) and its derivation from (d) simply beg the question against Davidson. (PT) is consistent, so far as has been shown, with authoritative self-ascription not based on the evidence available to a radical interpreter, and it entails that true ascriptions cannot conflict with what's recoverable by a radical interpreter. (PT) thus disallows the possibility that the subject's perspective could show up one assignment warranted by the interpreter's evidence as being right and the other wrong. Indeed, as we will see in a moment, the denial of (c) is not a hidden consequence of Davidson's position, but something he explicitly endorses. Without further development, then, Lepore and Ludwig have so far merely rejected $(\mathrm{PT})$, not provided an argument against it.

Again, one might reply on Lepore and Ludwig's behalf that I have omitted an important aspect of their argument: namely, that it speaks of how the radical interpreter must regard things. But emphasizing this feature of their presentation does not help. A first worry is that if the conclusion were just that radical interpreters must so regard things, it would not follow that things are so. Lepore and Ludwig cannot themselves endorse a transcendental argument from what radical interpreters must think to what is the case: their point is to undermine the alleged epistemic privilege such an argument presupposes. But even if they were read as running a transcendental argument strictly ad hominem, if it is not yet clear what grounds have been given for rejecting (PT), it is not yet clear what grounds a radical interpreter has for doing so. ${ }^{3}$

As with their first argument, Lepore and Ludwig, to rejoin, must challenge the claim that authoritative self-ascription cannot conflict with ascription warranted from the standpoint of a radical interpreter. How might such a rejoinder go?

\footnotetext{
${ }^{3}$ Note that if the possibility referred to in (c) is epistemic, then the possibility that one assignment is right and the other wrong remains open for the interpreter only if he does not himself accept (PT) and (E).
} 


\section{Davidson on the compatibility of first-person authority and indeterminacy}

The natural thought suggested by their argument is that a subject, from the first person perspective, in some sense has information that the radical interpreter lacks: namely, the deliverances of her capacity for first-person knowledge. Thus, although the radical interpreter's evidence does not suffice to select among multiple theories, the speaker's further information might. ${ }^{4}$

What information might that be? One possibility is that from the first-person perspective one simply knows that there is a fact of the matter about what one thinks (desires, intends, and so on) and about what one's words mean. But it is implausible that this knowledge, whatever it amounts to, could be freestanding. Rather, if we know something along these lines, it is because we know what the facts of the matter are in particular cases: we typically know what we think and what our words mean. Of course, Davidson agrees that we know such things. So, if knowing there is a fact of the matter about what one thinks is just knowing what one thinks, then Davidson can agree that in that sense one knows that there is a fact of the matter. But he denies that this is incompatible with (E) and with the resulting indeterminacy, according to which there is nothing further to be captured beyond what each of the equally acceptable truth-theories capture.

To see why he thinks this, consider a potential example of indeterminacy (based on Davidson 1997, pp. 80-1). A radical interpreter finds that the subject holds-true the sentence " $A$ is green" and not " $A$ is blue" in an environment where the interpreter expected, based on other evidence, that the speaker's judgments would be the reverse. Among the interpreter's options now are (1) to not alter his current semantic hypotheses but to ascribe a false belief, and (2) to ascribe a true belief while altering his semantic hypotheses. If the interpreter's language $\mathrm{L}_{\mathrm{I}}$ is similar (syntactically and lexically, but not necessarily altogether semantically) to $\mathrm{L}_{\mathrm{S}}$, that of the subject, the alternatives might involve $\mathrm{T}$-theories from which one can canonically derive:

(1) Stated in $\mathrm{L}_{\mathrm{I}}$ : "A is green" is true in $\mathrm{L}_{\mathrm{S}}$ iff $\mathrm{A}$ is green (and on this occasion the sentence the subject holds true is false in $\mathrm{L}_{\mathrm{S}}$ )

(2) Stated in $\mathrm{L}_{\mathrm{I}}$ : "A is green" is true in $\mathrm{L}_{\mathrm{S}}$ iff $\mathrm{A}$ is green or blueish [that is, blue towards the green end of the spectrum] (and the sentence the subject holds-true is indeed true in $\mathrm{L}_{\mathrm{S}}$ on this occasion)

\footnotetext{
${ }^{4}$ It seems obvious that Lepore and Ludwig intend their argument here to turn on this thought. I note, however, that their restatement of the challenge that first-person authority poses for Davidson takes a different form-one that reverts to the conflation between not conflicting with evidence available to a radical interpreter and being warrantedly ascribed only on the basis of such evidence:

The challenge can be expressed in the following argument:

(1) The justification for believing that something falls under a theoretical concept must be inferential.

(2) We have non-inferential knowledge of the contents of our psychological states and of the meanings of sentences in our language.

(3) Therefore, (these) psychological and linguistic concepts are not theoretical concepts. (2005, pp. 371-2)
} 
Suppose no other evidence or constraint available to the radical interpreter tells in favor of one alternative over the other, so that we have an example of alleged indeterminacy. Davidson maintains that this poses no threat to first-person knowledge and authority. The subject, we can suppose, holds-true the sentences "By 'green' I mean green (not: green or blue-ish)" and "I believe that A is green (not merely green or blueish)." The radical interpreter, we can suppose, will interpret these sentences-on either alternative - as expressing the subject's knowledge of what her words mean and of what she believes concerning $\mathrm{A}$ on this occasion. The interpreter can grant the subject first-person authority here: his interpretation is presumptively constrained to interpret these sentences so that they are true by the interpreter's own lights while plausibly optimizing otherwise her rationality and the truth of her beliefs. But that the interpreter makes these ascriptions and grants first-person authority does not render the information available to or recoverable by him in a way that selects among the alternative interpretations. For he has two alternatives for interpreting these sentences and for assigning content to the subject's relevant beliefs.

One might object that just because the subject authoritatively knows something, it does not follow that the interpreter knows, and thus can make use of the fact, that she does. For the subject need not report all that she knows; what she knows about what her words mean and what she thinks might then not be available to the interpreter. But this mistakes the situation in two ways. First, Lepore and Ludwig's suggestion above concerning the demands of rationality is that the interpreter does not need such evidence (for example, held-true sentences that are reports of such states), since the procedure of interpretation constrains him to ascribe these states in any event. The further claim here, on behalf of Davidson, is that what is thereby ascribed does not tell among alternative interpretations. Second, the interpreter nonetheless does have this evidence, since his having it does not require that the subject actually report such states. If an interpreter's evidential base were limited to held-true sentences actually uttered, Davidson would face a much larger problem concerning unmanifested beliefs generally - one not limited to beliefs about one's words' meaning and one's mental states. That dispositions are often unmanifested, at least not in ways available to a radical interpreter, would itself provide grounds for challenging the claim that the underdetermination amounts to indeterminacy-albeit not grounds essentially based on first-person authority.

This second point connects to an argument Lepore and Ludwig make in a different, but related, context. In real life, interlocutors do not, indeed cannot, report everything they know first personally - and they sometimes misreport it. Following Vermazen, Lepore and Ludwig thus criticize Davidson's attempted explanation of first-person authority. Davidson suggests the asymmetry in first-person and third-person belief ascriptions is explained by an asymmetry in first-person and third-person knowledge of meaning. A and B may both know that A holds-true some sentence $\mathrm{S}$ and therefore believes what $\mathrm{S}$ expresses. But only A knows presumptively what her words mean; so, only A knows presumptively what she believes. Lepore and Ludwig object that: 
An asymmetry in knowledge of meanings would seem adequate only if we restricted our attention to knowledge of thoughts which are expressed verbally, and which we are allowed to assume are sincerely expressed. Much of the asymmetry between our knowledge of our own and our knowledge of others' thoughts comes from our knowledge of thoughts to which we and they do not give verbal expression. (2005, p. 359)

Thus, Davidson's explanation succeeds only if other relevant asymmetries are already assumed. But even if this objection has force against Davidson's alleged explanation, its analog does not touch Davidson's claim that accurate first-person ascriptions cannot conflict with those of a radical interpreter. Davidson assumes that the radical interpreter knows what sentences the subject holds true in what environments. There is no claim that the radical interpreter is limited to sentences actually uttered by the subject. Likewise, the enterprise is not threatened by actually produced insincere reports. Since the interpreter knows what sentences the subject in fact holds true, he knows which actual reports are insincere or otherwise mistaken. ${ }^{5}$

So far, then, indeterminacy and first-person authority seem compatible. But, it will be objected, only in the sense that the interpreter's ascribing authoritative first-person knowledge does not enable him to remedy the underdetermination. And this will not satisfy someone who claims that first-person authority threatens the claim that this underdetermination is indeterminacy. For the worry is not that an interpreter cannot ascribe authoritative first-person knowledge, but that what the subject knows is not compatible with all of the various interpretations.

Davidson of course disagrees: the interpreter knows what the subject knows (albeit not authoritatively), but can equally well characterize it in multiple ways - why think there is something further left out? At least one source of the temptation to think otherwise, Davidson suggests, is the following picture of attitudes and attitude ascriptions: first, in having some attitude, a thinker stands in a relation to an object that (a) determines the content of the attitude, and (b) is fully present to the mind in a way that places the thinker in a position to know everything there is to know about the object;

5 Davidson says that holding true is "an attitude that may or may not be evinced in actual utterances" (2001 (1974), p. 143). It may be thought that nonetheless it must be evinced in actual behavior. But his writings support at most that it be evinced in "actual or potential" behavior (2001 (1979), pp. 227, 230, and cf. p. 236). In fact, as Lepore and Ludwig discuss (2005, pp. 157-8), it is unclear whether Davidson's considered view includes even this — at least if this requires that the interpreter ultimately be able to justify ascriptions of hold-true attitudes on the basis of (non-intentionally described) actual or potential behavior, or behavioral dispositions. But if such justification is needed, it is less clear whether the problem of insincerity can be turned aside. (Perhaps insincerity is only coherent against a background of sincerity, so that there is a limit to how much a radical interpreter can mistakenly ascribe attitudes owing to a subject's insincerity. But the existence of such a limit does not preclude some mistaken attributions.) Lepore and Ludwig's view is that Davidson does require a grounding of hold-true attitudes in behavior, and that whether he does affects how one must evaluate some of his arguments. (The argument currently under discussion, however, is not among those they single out as affected by this interpretive question.)

Also, as Lepore and Ludwig note (2005, p. 177, fn. 149), it is not trivial to assume that subjects have a holdtrue attitude towards each belief-expressing sentence. However, they do not consider this assumption to be particularly problematic. 
second, in ascribing a thought, one relates the thinker to such objects, relevantly differing that-clauses referring to different such objects. If the subject stands in such a relation, and the interpreter's alternative hypotheses would relate her to one or another such object, then presumably there is a fact of the matter as to which of the two objects is indeed present to the subject's mind. What is more, the subject knows which object it is - something the radical interpreter would know as well if only he could have access to the subject's subjective state. But Davidson rejects this conception both of attitudes and attitude ascriptions. He argues that there can be no such objects, and offers an alternative "paratactic" view of attitude ascriptions. ${ }^{6}$ Can one nonetheless challenge Davidson without committing oneself (at least not obviously so) to the tempting picture?

\section{Lepore and Ludwig's objection that indeterminacy is problematic}

Lepore and Ludwig do argue that a radical interpreter cannot recover the semantic facts. But whereas the previous section's idea was to focus on the subject's first-person knowledge, they argue that an interpreter's knowledge of what his own words mean renders it incoherent for him to accept differing truth-theories concerning the subject's. That is, he cannot equally well characterize in multiple ways what the subject's words mean and what her attitudes are (including what she knows first-personally about them). Not only is it possible that one of his assignments is wrong, it cannot be that both are right.

For suppose he confirms two theories for a language $L$, designated as the language of a particular speaker, according to one of which (1) is true, and according to the other of which (2) is true. The interpreter also knows that (3) is true, and therefore that (4) is.

(1) "Alpha is a gavagai" means in $L$ that Alpha is a rabbit.

(2) "Alpha is a gavagai" means in $L$ that Alpha is a squirrel.

(3) "rabbit" is not synonymous in English with "squirrel."

(4) "Alpha is a rabbit" does not mean in English the same as "Alpha is a squirrel."

However, from (4) (and the assumption that if $\mathrm{S}$ means in $L$ that $\mathrm{P}$ and means in $L$ that $\mathrm{Q}$, then "P" and "Q" do not mean the same) it follows that (1) and (2) cannot both be true, and, since they are consequences of the different meaning theories he can confirm, at least one theory must be incorrect. (2005, pp. 239-40)

\footnotetext{
${ }^{6}$ Davidson sums up his rejection of such objects as follows: "The only object that would satisfy the twin requirements of being before the mind and also such that it determines the content of a thought must, like Hume's ideas and impressions, 'be what it seems and seem what it is'. There are no such objects, public or private, abstract or concrete" (2001 (1987), p. 37). See Davidson (2001 (1968)) for his paratactic account of attitude ascription, defended in Lepore and Ludwig (2007, ch. 11).
} 
This argument, however, is the centerpiece of Lepore and Ludwig's other main challenge to (PT): their objection that indeterminacy is problematic. ${ }^{7}$ The objection from problematic indeterminacy is clearly presented as independent of the objection from first-person authority. If we defend the objection from first-person authority by drawing upon the objection from problematic indeterminacy, we collapse the two challenges into one. This, of course, is not a problem with the argument, to which any defense of Davidson would have to respond. But the soundness of the objection from problematic indeterminacy is not our topic here (though cf. fn. 8). What we will ask is whether it essentially draws upon first-person authority.

Lepore and Ludwig's argument from problematic indeterminacy depends on a particular conception of interpretive truth-theories and of the interpreter's goal. A truth-theory, on this conception, is interpretive if the meaning-sentences corresponding to its T-theorems (that is, for " $\mathrm{S}$ is true in L iff $\mathrm{p}$," the sentence " $\mathrm{S}$ means in L that p") are true; and a radical interpreter succeeds in interpreting a subject if the truth-theory his procedure yields is interpretive. Lepore and Ludwig acknowledge that it is unclear that Davidson would endorse this conception: one can find text both in support and against. But they argue (2005, p. 96, fn. 86; pp. 152-66) that it is a conception he could and should accept. It is perhaps not surprising that it is difficult to square this criterion of success for radical interpretation - that it yield, in some particular case, that $\mathrm{S}$ means that $\mathrm{p}$-with the claim that, although radical interpretation can succeed, it is indeterminate, or there is no fact of the matter, whether S means that $\mathrm{p}$. Perhaps this tension might even count as evidence against Lepore and Ludwig's claims concerning what Davidson does and could accept. It is thus worth asking whether their argument could survive in some form if this conception were not assumed.

Indeed it can, at least with respect to certain cases of indeterminacy-but at the cost of severing any tie to first-person authority. Suppose it is known that (5) and (6) follow from truth-theories well-confirmed in application to a particular subject from the epistemic position of a radical interpreter.

(5) "Alpha is a gavagai" is true in L iff Alpha is a rabbit.

(6) "Alpha is a gavagai" is true in L iff Alpha is a squirrel.

(5) and (6) entail:

(7) Alpha is a rabbit iff Alpha is a squirrel.

But (7) is false. So it cannot be the case that both (5) and (6) are true. ${ }^{8}$ One can run this argument only for cases of indeterminacy involving extensionally inequivalent sentences.

\footnotetext{
${ }^{7}$ Lepore and Ludwig (2005, p. 239) also argue that the indeterminacy would be too extensive to be plausible.

${ }^{8}$ Davidson credits this objection to Ian Hacking and replies: "[Sentences (5) and (6) do not yield] a contradiction if the theories are relativized to a language, as all theories of truth are. Our mistake was to suppose there is a unique language to which a given utterance belongs. But we can without paradox take that utterance to belong to one or another language, provided we make allowance for a shift in other parts of our
} 
But that provides limited comfort for Davidson. Though Lepore and Ludwig intend to impeach indeterminacy more generally, it is a sufficient challenge that some cases of indeterminacy Davidson endorses are problematic. More important for our purposes, however, is that, as mentioned, this argument abandons the tie to first-person authority. To maintain otherwise, one would need to argue - implausibly - that the justification of (7)'s negation essentially includes one's first-person knowledge of what "rabbit" and "squirrel" mean. ${ }^{9}$

Having noticed this, we should return to Lepore and Ludwig's own argument. For it might be suggested that it too does not crucially rely on first-person knowledge. After all, it is plausible that any well-confirmed interpretation of the interpreter himself would yield (3) and (4). This would suffice to render (1)-(4) incoherent, so that not all the meaning-theories confirmable from the epistemic position of a radical interpreter could be true. It might be replied that even if an appeal to first-person knowledge is not essential to showing that not all the interpretations in play could be true, such an appeal is essential for reaching the more specific conclusion that (1) or (2) - not the interpretation made of the interpreter-is at fault. But even that is unclear. If any interpretation of the interpreter would yield (3) and (4), then, if these interpretations were all

total theory of a person" (2001 (1979), pp. 239-40). Lepore and Ludwig have three rejoinders. The firstthat one could formulate the theories without reference to language, for example by relativizing truth and meaning (and so on) to the speaker (2005, p. 240, fn. 200)-would indeed require Davidson to otherwise relativize these alternative formulations without running into other troubles (and Lepore and Ludwig do critically discuss other candidate relativizations). According to the second: “. . if each is just as good a theory of the speaker's language, but they are different languages, we are committed to saying that his language is identical to each of two distinct ones not identical to each other, which is a contraction" (2005, p. 240 , fn. 200). But this does not take sufficiently seriously Davidson's suggestion that, at least in the relevant sense, there is no language that is the language of the speaker and thus none that is identical with different languages not identical to each other. Arguably, this move, far from being ad hoc, is just what someone committed to indeterminacy should make: if there is indeterminacy, and if language's are individuated in part by what their expressions mean or what the expressions' truth-conditions or contributions to truth-conditions are, then it is likewise indeterminate what a person's language is. There are, of course, serious obstacles which a development of this suggestion would have to overcome; but, by objecting where they do, Lepore and Ludwig mislocate what is problematic about it. Finally, when they later (2005, pp. 384-5) revisit Davidson's reply to Hacking, Lepore and Ludwig advert to their earlier (2005, pp. 243-7) challenge to Davidson's measurement theory analogy. Davidson (for example, 2001 (1989), pp. 59-65) suggests that we should be no more bothered by the fact that a subject's attitudes and meanings can be variously equally well characterized than we are bothered by the fact that we can just as well characterize temperature in Farenheit or Centigrade. (That characterizations in Kelvin are even better for some purposes is not relevant here.) Lepore and Ludwig reply that empirical patterns can be variously tracked by objects in a mathematical structure only if the mathematical structure is essentially richer in the sense of allowing distinctions that have no application to the empirical patterns. Applied to the case of radical interpretation, we then reach the absurdity that a language can be richer than itself-since radical interpretation does not preclude an interpreter's language from being the same as the subject's. Put aside the reference to the language of a speaker. Still, although it is true that the real numbers are richer than empirical patterns among temperatures, Lepore and Ludwig do not elaborate on why one should think in general that the measuring structure must be richer if there are to be various ways of measuring. What rules out in principle a physical structure as rich as a measuring structure that has non-trivial automorphisms?

9 This is perhaps less implausible, though still highly non-obvious, in other cases: for example, Davidson's green vs. green or blueish case. 
incorrect, the interpreter would be uninterpretable. Perhaps this consideration suffices for pinning the blame rather on (1) or (2).

Perhaps, however, there are at least in certain cases more specific conclusions the interpreter can reach by adverting essentially to first-person knowledge-specifically, his first-person knowledge of what his own words mean and do not mean. Suppose, in particular, that the language of the interpreter is the language of the subject. In such cases, if the interpreter knows that "Alpha is a rabbit" means in $\mathrm{L}_{\mathrm{I}}$ that Alpha is a rabbit and does not mean in $\mathrm{L}_{\mathrm{I}}$ that Alpha is a squirrel, conclusions follow concerning which of the various theories confirmed through radical interpretation can be correct. Note, however, that the interpreter in pursuing radical interpretation cannot make use of the knowledge, if he has it, that his language is the subject's: such knowledge is precluded from the interpreter's evidential base. So, whereas the the interpreter qua interpreter can conclude in Lepore and Ludwig's argument that at least one assignment must be wrong, he cannot himself qua interpreter reach the more specific conclusion.

Still, the conclusion would seem to follow, ${ }^{10}$ even if one is unable to see this from the perspective of the radical interpreter. Moreover, it is harder to argue here, as we suggested above, that this knowledge (that "Alpha is a rabbit" means in $\mathrm{L}_{\mathrm{I}}$ that Alpha is a rabbit and does not mean in $\mathrm{L}_{\mathrm{I}}$ that Alpha is a squirrel) could also be had non-firstpersonally by an interpreter of the interpreter. First, he would not know (qua radical interpreter) that "Alpha is a rabbit" does not mean in $\mathrm{L}_{\mathrm{I}}$ that Alpha is a squirrel. At least, if Lepore and Ludwig allowed that he did, then there would be an even more direct argument, not adverting to first-person knowledge of meaning, that multiple truththeories lead to contradiction. For then we would have both that "Alpha is a rabbit" does and does not mean in $\mathrm{L}_{\mathrm{I}}$ that Alpha is a rabbit - and, similarly, both that it does and does not mean in $\mathrm{L}_{\mathrm{I}}$ that Alpha is a squirrel. ${ }^{11}$ But if what the interpreter of the interpreter knows is (a) that "Alpha is a rabbit" means in $\mathrm{L}_{\mathrm{I}}$ that Alpha is a rabbit, and (b) that "Alpha is a rabbit" means in $\mathrm{L}_{\mathrm{I}}$ that Alpha is a squirrel, then there is no basis for determining which of the interpretations of the original subject is incorrect. In any event, second, if we are granting Lepore and Ludwig's objection, and now just looking to extend it in a way that essentially adverts to first-person knowledge of meaning, then we should not grant the interpreter of the interpreter any knowledge of what "Alpha is a

10 But see Davidson's (2001 (1997), pp. 79-80) remarks, presumably in reply to Searle (1987) or views like his, concerning homophonic self-ascriptions. Discussing this would take us even further away from Lepore and Ludwig's own arguments. But I note that Davidson would need to say more to handle authoritative "does not mean" claims of the sort adverted to above.

11 Bracketing refinements, Lepore and Ludwig (2005, pp. 120-1) maintain that S means in L that p iff an interpretive truth-theory yields that $\mathrm{S}$ is true in $\mathrm{L}$ iff $\mathrm{p}$. Suppose it is not assumed or already established that there cannot be more than one interpretive truth theory for a language. Then, if "an" means here "at least one," not "any," then from the fact that some one interpretive truth-theory does not yield that S is true in L iff $\mathrm{p}$, it does not follow that S does not mean in L that p. If, however, it means "any," then, if there are two interpretive truth theories such that $\mathrm{S}$ is true in $\mathrm{L}$ iff $\mathrm{p}$ (but not iff $\mathrm{q}$ ) according to one, and $\mathrm{S}$ is true in $\mathrm{L}$ iff $\mathrm{q}$ (but not iff $\mathrm{p}$ ) according to the other, then it would follow that $\mathrm{S}$ does not mean in $\mathrm{L}$ that $\mathrm{p}$ and $\mathrm{S}$ does not mean in $\mathrm{L}$ that $\mathrm{q}$ - and nothing positive would follow about what $\mathrm{S}$ does mean. 
rabbit" means in $\mathrm{L}_{\mathrm{I}}$. He might, as claimed above, have some knowledge of what expressions are not synonymous in $\mathrm{L}_{\mathrm{I}}$. But that is because such claims, unlike claims concerning what sentences mean, are arguably not underdetermined by the evidence available to a radical interpreter.

That said, that an interpreter of the interpreter cannot know these meaning facts does not imply that they can only be known first-personally. We must ask whether someone else besides the interpreter and who is not constrained to the epistemic position of a radical interpreter can know what the interpreter's words mean. The answer certainly seems to be "yes." It is plausible that actual speakers are often in a position to know that their interlocutors' language (or a relevant fragment) is the same as their own, and are thus in a position to know what their interlocutors' words mean-in particular, in a position to know something of the form " $\mathrm{S}$ means in L that p." For speakers know what their own words mean and, presented with language seemingly similar phonologically, syntactically, and so on, will unreflectively presume that it is the same language as their own, with the same semantics. Insofar as the presumption is warranted and what is presumed is in some particular case true, this amounts to knowledge of what the others' words mean. (Of course, what is presumed need not always obtain, and a speaker can realize that it does not in some particular case: arguably, this is what occurs in Davidson's real-life "green" vs. "green or blueish" case.) If this model is on the right track, we can know what others' words mean nonfirst-personally. Even if there is a presumption that attaches in the circumstances to the belief that the other speaks the same language, it is not a first-personal presumption and not - or, at least not obviously — itself somehow grounded in knowledge of one's own mental states and the meanings of one's own words. It nonetheless remains the case that on this model one has knowledge of what the other's words mean in part owing to one's knowledge of what one's own words mean: the non-first-personal knowledge that the other speaks the same language does not itself suffice. So, first-person authority would still play a role in providing warrant for the premise in the extended version of Lepore and Ludwig's argument. It is worth noting, though, that since actual speakers, unlike radical interpreters, are not precluded from drawing on their knowledge that another speaks the same language and thus that their words mean such-and-such, actual speakers can complete the inference to which interpretation is incorrect. (Indeed, they can do this without a detour through knowledge of what the interpreter's words mean. If they speak the same language as the interpreter, then they speak the same language as the original subject and so can come to know this and thus what the original subject's words mean without concerning themselves with the interpreter.) If in fact speakers can sometimes know what others' words mean but radical interpreters cannot, then so much more the worse for radical interpreters.

So, Lepore and Ludwig do not seem to have an objection to Davidson from first-person authority that is independent of their objection from problematic indeterminacy. And it is unclear that the objection from problematic indeterminacy requires adverting to first-person authority at all. Nonetheless, adding to the argument from 
problematic indeterminacy what is known first-personally about meaning, or known in part on the basis of something known first-personally about meaning, does seem to imply further, more specific conclusions - at least if the argument from problematic indeterminacy succeeds in the first place. These are conclusions, however, that are not available to the radical interpreter himself. The extended argument, therefore, differs in character from Lepore and Ludwig's: it does not characterize an incoherence that the interpreter can himself discern from his perspective as a radical interpreter.

\section{Indeterminacy and non-first-personal evidence not available to a radical interpreter}

We have been exploring whether first-person evidence resolves underdetermination relative to a radical interpreter's epistemic position and thus tells against indeterminacy and (E). We conclude by briefly noting the possibility that other evidence, not available either first-personally or to a radical interpreter, may do so.

What is available first-personally and what is available to a radical interpreter do not exhaust the possibilities. And indeed, practicing semanticists advert to evidence that falls in neither category. (For an overview of evidence in semantics, cf. Krifka 2011.) To be sure, much of it is available one way or the other. Consider, for example, speakers' semantic "intuitions" concerning not only truth-conditions, but also entailment, ambiguity, and so on, which Davidson (1967, for example) himself famously draws upon when defending specific semantic proposals, and which Lepore and Ludwig (2005, p. 124) emphasize are a "primary (though not inviolable) source of data." These intuitions - relatively immediate and unreflective judgments, or appearances, concerning semantically relevant matters - arguably fall within the purview of first-person authority. In any event, since they can be reported, they are arguably available to a radical interpreter. (Even if the "intuition" is in some sense based on a distinct phenomenological state, what can be reported suffices to play its evidential role.) Of course, the interpreter must have a provisional theory up and running in order to interpret such reports-which requires already having hypotheses concerning, for example, entailment. But any acceptable theory will have to accommodate in the end all admissible evidence, including the evidence supplied by such reports. Thus can a native speaker serve as an informant even to a radical interpreter (cf. Lepore and Ludwig 2005, p. 197, fn. 172). Other sources of evidence which semanticists draw upon are likewise available to a radical interpreter, since he has access not only to what sentences are held-true in what circumstances, but also to "readily observable" behavior (Davidson 2005, p. 56). Thus, at least on a generous construal of "readily observable," corpus and cross-linguistic data, for example, fall within his purview. But some evidence is available neither first-personally nor, on any reasonable interpretation of "readily observable," to radical interpreters. Obvious examples include fine-scale evidence concerning reaction times, eye position, and pupil dilation, as well as 
physiological responses measured in EEG, fMRI, and related studies. On this, Davidson is clear: a radical interpreter "hasn't learned what someone thinks or means by opening up his brain.... I restrict the evidence to what would be plainly available to an observer unaided by instruments" (1994, pp. 125 and 127).

But is there reason to think that such evidence could tell among truth-theories underdetermined by the evidence available to a radical interpreter? It is certainly far from obvious that it could settle underdetermination of the sort Davidson emphasizes: that due to (alleged) inscrutability of reference (Lepore and Ludwig 2005, ch. 21, argue that this is in fact not a source of underdetermination), and that due to the "blurring" of the analytic/synthetic distinction and the subsequent possibility of trade-offs between ascriptions of attitudes and assignments of meaning (as in the green vs. green or blueish case). But such evidence might settle other kinds of underdetermination. To illustrate the in-principle possibility, consider a toy case of disagreement over lexical ambiguity. ${ }^{12}$ A first truth-theory, say, distinguishes two nouns of the orthographic form "drink": roughly, one for liquids one drinks, and the other more specifically for alcohol one drinks. A second truth-theory recognizes only the first meaning. It handles utterances such as "I need a drink," made gesturing towards the bar after a stressful event witnessed by the intended recipient, by adverting to pragmatic processes any overall theory must include, so that, on this occasion, the truth-conditions of the uttered sentence and the truth-conditions of what is saliently communicated by the speaker diverge. Put aside that the orthographic form may have other meanings, that these two truth-theories do not exhaust the possibilities, and that there might be examples that are more plausibly "hard cases" than this one. In cases of this sort, assuming the evidence available to radical interpreters underdetermines the alternatives, one can more readily see how non-first-personal, non-readily-observable evidence could help settle the matter. This is because, unlike with Davidson's primary examples, the disagreement concerns, first, the number of truth-theoretic axioms, not just their content (cf. the use of truth-theories with different numbers of axioms in discussions of "tacit knowledge"; for example, Evans 1981), and, second, the proper apportionment of responsibility between semantics and pragmatics. Regarding the first, we can ask whether dissociations are possible: whether the disposition to use one noun "drink" could be lost or acquired independently of the other (cf. Lepore and Ludwig 2005, p. 123.) We can also ask whether there is evidence that distinct neural areas implicated in long-term memory are implicated in the production and understanding of sentences involving the two hypothesized terms. Regarding the second, we can ask, for example, whether subjects comprehending the

\footnotetext{
${ }^{12}$ If a radical interpreter already knows what sentences are held true, will he already distinguish two otherwise identical sentences containing a lexically ambiguous constituent? No, for then sentences would be individuated in part in terms of the semantic properties of their constituents, which would import a precluded semantic notion into the conception of sentences used to characterize the epistemic position of a radical interpreter.
} 
"I need a drink" utterance described above exhibit the N400 EEG effect-a characteristic dip around $400 \mathrm{~ms}$ associated with increased demands on semantic integration and exhibited, for example, in the interpretation of metaphor-which arguably would favor the second truth-theory. We can also ask whether processing times differ between such utterances and comparable utterances where the speaker's meaning is not restricted to alcoholic drinks. Not that it would be easy to settle the matter-but we are just considering what could be in principle.

Cases of disagreement over lexical ambiguity, while they may make it easier to see how such evidence could settle underdetermination, arguably suffer along a different dimension in comparison to at least some of Davidson's cases of indeterminacy; for it is not obvious that the evidence available to a radical interpreter in fact would underdetermine truth-theories regarding these matters. Many tests for ambiguity, for various pragmatic processes, and so on, have been proposed that draw on evidence available to a radical interpreter, even if there is also much disagreement both about the tests and about what they yield in particular cases. That there would be underdetermination — or at least that it is epistemically possible for us now that there would be-is important for our point, because the question is not whether non-first-personal, not-readily-observed evidence is so much as relevant to semantic claims, but rather whether the evidence available to a radical interpreter-that subset of evidencesuffices to settle the semantic facts on its own. (This is the analog to the distinction drawn above in replying to Lepore and Ludwig's first objection from first-person authority.)

Some might object that that this non-first-personal, not-readily-observed "evidence" in fact is not even relevant: it bears on a subject's semantic competence, or on the mechanisms and states that underlie that competence, but not on the semantic facts of her language. (Cf. Soames 1984, but also Antony 2003, in response.) But this objection is not one that Lepore and Ludwig would endorse-nor, they argue, should Davidson. On their view, there is an intimate connection between semantics and semantic competence:

... an interpretive truth theory represents the structure of the ability to speak a language by having an axiom for each primitive which correctly encodes its semantical role, and referent or application conditions. This corresponds to a disposition in a competent speaker to use the word in accordance with its semantic role and reference or application conditions. (2005, p. 124)

Indeed, they argue, it is this connection that enables us to have intuitions concerning our own languages and thus provides a major source of evidence for semantics.

Davidson's own writings, as Lepore and Ludwig discuss (2005, pp. 121-2), are not clear on the matter- perhaps they display an ambivalence. But although some of his remarks can be read as requiring nothing more than that the truth-theory's T-theorems correctly capture the truth-conditions the speaker associates with a sentence, Davidson affirms that: 
Since people can understand (that is, know the truth-conditions of) arbitrary sentences they have never heard, I did assume they somehow process them on the basis of their understanding of the semantic properties of the items in a finite vocabulary and rules for deriving the truth-conditions of sentences from these properties and rules. (1999, p. 251)

He adds that he is:

a realist about psychological descriptions, but I didn't suppose that on the basis of largely a priori reasoning I (or anyone else) could arrive at a detailed knowledge of how our brains process sentences. $(1999$, p. 251)

Elsewhere, Davidson (2005 (2001), pp. 291-4) expresses excitement concerning the novel empirical methods developed in the sciences of the mind and brain, and argues for their philosophical relevance (as well as the need for philosophical interpretation of their results). To rule out - "on the basis of largely a priori reasoning"-the possibility of underdetermination settled by non-readily observable, non-first-personal evidence, one would need a compelling argument for (E).

\section{References}

Antony, L. 2003. Rabbit-Pots and Supernovas: On the Relevance of Psychological Data to Linguistic Theory. In A. Barber (ed.), Epistemology of Language. Oxford: Oxford University Press, pp. 47-68.

Davidson, D. 1994. Radical Interpretation Interpreted. Philosophical Perspectives, 8: 121-8. 1999. Reply to Tyler Burge. In L. Hahn (ed.), The Philosophy of Donald Davidson. Chicago:

Open Court, pp. 251-4.

2001 (1967). Logical Form of Action Sentences. In Essays on Actions and Events, 2nd edn., Oxford: Oxford University Press pp. 105-21. Originally published in N. Rescher (ed.), The Logic of Decision and Action. Pittsburgh: University of Pittsburgh Press. 2001 (1968). On Saying That. In Inquiries into Truth and Interpretation, 2nd edn., Oxford:

Oxford University Press pp. 93-108. Originally published in Synthese, 19: 130-46.

2001 (1973). Radical Interpretation. In Inquiries into Truth and Interpretation, 2nd edn., Oxford: Oxford University Press pp. 125-39. Originally published in Dialectica, 27, (1973): 314-28.

2001 (1974). Belief and the Basis of Meaning. In Inquiries into Truth and Interpretation, 2nd edn., Oxford: Oxford University Press pp. 141-54. Originally published in Synthese, 27: $309-23$

2001 (1979). The Inscrutability of Reference. In Inquiries into Truth and Interpretation, 2nd edn., Oxford: Oxford University Press pp. 227-41. Originally published in Southwestern Journal of Philosophy, 10 (1979): 7-20.

2001 (1984). First Person Authority. In Subjective, Intersubjective, Objective, Oxford: Oxford University Press pp. 3-14. Originally published in Dialectica, 38 (1984): 101-12.

2001 (1987). Knowing One's Own Mind. In Subjective, Intersubjective, Objective, Oxford: Oxford University Press pp. 15-38. Originally published in Proceedings and Addresses of the American Philosophical Association, 60: 441-58. 
Davidson, D. 2001 (1997). Indeterminism and Antirealism. In Subjective, Intersubjective, Objective, Oxford: Oxford University Press pp. 69-84. Originally published in C. B. Kulp (ed.), Realism/ Antirealism and Epistemology. Lanham, Maryland: Rowman \& Littlefield.

2001 (1998). The Irreducibility of the Concept of the Self. In Subjective, Intersubjective, Objective, Oxford: Oxford University Press pp. 85-91. Originally published in M. Stamm (ed.), Philosophie in synthetischer Absicht. Stuttgart: Klett-Cotta.

2005 (2001). Aristotle's Action. In Truth, Language, and History, Oxford: Oxford University Press pp. 277-94. Originally published in French in Quelle Philosophie pour le XXI ${ }^{e}$ Siècle. Paris: Gallimard/Centre Pompidou.

Evans, G. 1981. Semantic Theory and Tacit Knowledge. In S. Holtzman and C. Leich (eds.), Wittgenstein: To Follow a Rule. London: Routledge.

Krifka, M. 2011. Varieties of Semantic Evidence. In C. Maienborn, K. von Heusinger, and P. Portner (eds.), Semantics: An International Handbook of Natural Language Meaning, Vol. I. Berlin: Mouton de Gruyter, pp. 242-67.

Lepore, E. and Ludwig, K. 2005. Donald Davidson: Meaning, Truth, Language, and Reality. Oxford: Oxford University Press.

2007. Donald Davidson's Truth-Theoretic Semantics. Oxford: Oxford University Press.

Searle, J. 1987. Indeterminacy, Empiricism, and the First Person. Journal of Philosophy, 84: 123-46.

Soames, S. 1984. Linguistics and Psychology. Linguistics and Philosophy, 7: 155-79. 